\title{
BOREDOM IN ACUTE PSYCHIATRIC CARE
}

By: Mona M. Shattell

Shattell, M. (2007). Boredom in acute psychiatric care. Issues in Mental Health Nursing, 28(6), 661-662.

Made available courtesy of Taylor and Francis:

http://www.informaworld.com/smpp/title $\sim \mathrm{db}=\mathrm{all} \sim$ content $=\mathrm{t} 713669522 \sim \mathrm{tab}=\mathrm{issueslist}$

\section{***Note: Figures may be missing from this format of the document}

Patients hospitalized in acute care psychiatric settings often complain of boredom. Neither historical context nor geographical settings seem to make a difference. Boredom can be found in contemporary studies and older studies, in studies in the United States and the United Kingdom (Raphael, 1974; Raphael \& Peers, 1972; Shields, Morrison, \& Hart, 1988; Thomas, Shattell, \& Martin, 2002). Boredom does not seem to correlate to how long a person has been in the hospital or model of health care delivery. Perhaps you can understand how patients would get bored after a 2-3 month stay as was customary in the past, but not today, with short 3-5 day hospitalizations. How do patients have time to be bored?

What might psychiatric nurses who work in inpatient settings say is the cause of patient boredom? What might their response to this complaint be? Might they say, "We are not here to entertain patients," or, "this quiet time away from all the stressors of real life should be enjoyed and reveled in, not shunned with distain?" Perhaps they would say, "I wish we could do more with and for our patients, but we just do not have enough staff."

Reasons for patient boredom may be many. Are patients bored because they do not have enough to do to occupy their time? Is there a lack of stimulation in the bland, stark psychiatric units that are kept this way in the name of safety? Are there inadequate group therapy and psychoeducational sessions, or too few individual interactions with psychiatric mental health nurses? Is it that patients are used to their other roles in other settings-work, home, friends, family, etc. - that we strip from them when they are hospitalized?

The absence of typical roles, not necessarily the addition of the "patient" role, contributes to an absence of meaning (Binnema, 2004). Higgins, Hurst, and Wistow (1999) relate boredom to lack of nurse-patient relationships: "Many patients had only passing relationships with nurses who were in the office writing or telephoning or dealing with unexpected incidents in the ward. This resulted in the boredom reported by many patients who, when in hospital, felt they were often left to their own devices" (p. 59). This finding is consistent with those of Thomas et al. (2002) and Shattell (2002).

According to Binnema (2004), "boredom registers an absence of meaning through roles and relationships, an absence of meaning implies a lack of a sense of control, and a lack of a sense of control is associated with ill health" (p. 840). Binnema (2004) suggests, and I agree, that hospital environments should pay attention to patient boredom because of its negative affect on mental 
health. However, this requires health care professionals and administrators to accept seriously, patients' complaints of boredom. According to Shields et al. (1988), "the whole problem is the inevitable resistance of professionals to consumer feedback, with its implications of criticism" (p. 400). When are we going to accept patient boredom as a real problem?

REFERENCES

1. Binnema, D. (2004) Interrelations of psychiatric patient experiences of boredom and mental health. Issues in Mental Health Nursing 25 , pp. 833-842.

2. Higgins, R., Hurst, K. and Wistow, G. (1999) Nursing acute psychiatric patients: A quantitative and qualitative study. Journal of Advanced Nursing 29:1, pp. 52-63.

3. Raphael, W. (1974) Just an ordinary patient King's Fund, London

4. Raphael, W. and Peers, V. (1972) Psychiatric hospitals viewed by their patients King's Fund, London

5. Shattell, M. Thomas, S. and Pollio, H. (eds) (2002) Eventually it'll be over: The dialectic between confinement and freedom in the world of the hospitalized patient. Listening to patients: A phenomenological approach to nursing research and practice pp. 214-236. Springer, New York

6. Shields, P., Morrison, P. and Hart, D. (1988) Consumer satisfaction on a psychiatric ward. Journal of Advanced Nursing 13 , pp. 396-400.

7. Thomas, S., Shattell, M. and Martin, T. (2002) What's therapeutic about the therapeutic milieu?. Archives of Psychiatric Nursing 16:3, pp. 99-107. 